P65 (continued)

meeting recommendations for vegetable intake. Future child-care based interventions should consider targeting dietary intake outside the child-care setting as it may have a significant role in obesity risk.

Funding: National Heart Lung and Blood Institute

\section{P66 Challenges and Barriers to Providing Healthy Lifestyle Opportunities in Child Care Centers}

Cynthia A. Warren,PhD, cwarren2@twu.edu, Texas Woman's University, 1200 Frame Street, Denton, TX, 76209; Katherine K. Rose, PhD, Texas Woman's University

Objective: Child care provides an optimal environment to influence young children's relationship with nutritious food and physical activity. More than two-thirds of children between 3 and 5 years of age attend some form of child care each week. The purpose of this study was to obtain in-depth information through focus group discussions to understand child care centers' directors, teachers and staff perceived challenges and barriers to providing healthy lifestyle opportunities to preschool children in their care.

Study Design, Setting, Participants, Intervention: A list of licensed center-based programs in Denton County (TX) was generated from the Texas Department of Family Services website $(n=234)$ and each center mailed a recruitment flyer. Resulting audio-taped sessions were transcribed verbatim.

Outcome Measures and Analysis: Five focus groups, lasting approximately 50 minutes each, were conducted with 46 Denton County (TX) child care providers (teachers, directors, cooks, and owners). The resulting transcripts were read, data unitized, coded and compared, thematically categorized and interpreted using a grounded approach.

Conclusions and Implications: Time, convenience, cost and lack of nutrition knowledge were major underlying themes emerging from these discussions. Findings indicate the lack of affordable, evidence-based nutrition education materials available for child care providers, parents and preschoolers. Additional findings include educating parents and providers on how to prepare budget-friendly nutritious foods for children, as well as easy-to-use methods for getting children to try new foods, was another finding. Study findings will inform future intervention research that promotes the healthy development of young children.

Funding: Texas Woman's University

\section{P67 Child Centered Nutrition Phrases: Messaging Increases Young Children's Consumption of Healthful Foods}

Jane Lanigan, PhD, jlanigan@wsu.edu, Washington State University, 14204 NE Salmon Creek Avenue, Vancouver, WA 98686; Rachel Bailey, PhD, Washington State
University; Samantha Ramsay, $P h D, L D N, R D$, University of Idaho; Valerie Jarvensivu, MS, Washington State University

Objective: Communication strategies that promote young children's healthful eating have received limited empirical study, particularly in early childhood education (ECE) settings. This study examines the effect of developmentally appropriate nutrition phrases on young children's food behavior.

Study Design, Setting, Participants: Eighty-seven children aged 3-6 years attending two ECE programs participated in a within-subject experiment. For the sixweek taste activity intervention, each child was randomly assigned a repeated exposure (RE) and a child-centered nutrition phrase (CCNP) food (quinoa, lentils, tomato, or bell pepper).

Outcome Measures and Analysis: A consumption trial measured individual intake pre- and post-treatment and at one month post-treatment. Grams consumed data were log-transformed then submitted to a 2-level random effects model with time of assessment, phrase condition, their interaction, pre-preference for the foods, and pre-exposure to the foods at level 1; and site, child age, income, parent education level, and parent nutrition knowledge at level 2. Results: Consumption of the CCNP food across the sample increased more than foods using RE alone. Children exposed to the CCNPs consumed $8.95 \mathrm{~g}$ more of their target food post-treatment and $17.9 \mathrm{~g}$ more at the one month post-assessment. A site effect was detected. Children from one ECE program accounted for the increased consumption of the CCNP food within the sample. Children attending the second site consumed less of the CCNP food than the RE food.

Conclusion and Implications: Strategic use of developmentally appropriate nutrition messaging in ECE programs may be an effective strategy for increasing food consumption, but further research is needed to better understand contextual factors.

Funding: University of Technology, Jamaica Research Development Fund

\section{P68 Culturally Relevant Nutrition Education for Migrant Head Start Parents 2016}

Imelda Galdamez, MSW, imeldagaldamez@gmail.com, Michigan State University Extension, 446 West Circle Drive, Room 257, East Lansing, MI 48824;

Courtney Cuthbertson, PhD, Michigan State University Extension; Andrea Aguilar, MS

Objective: Michigan State University Extension implemented a process to design and deliver a culturally and linguistically relevant program to seasonal and migrant workers who were parents of young children during summer 2016.

Description: Michigan State University Extension partnered with a migrant worker service agency to provide culturally-relevant nutrition and physical activity education to seasonal and migrant worker parents with 